\title{
Nonsyndromic proximal aortic aneurysms: What size matters?
}

\author{
Luca A. Vricella, MD, FACS
}

\author{
From the Division of Cardiac Surgery, The Johns Hopkins University, Baltimore, Md. \\ Received for publication Aug 30, 2016; revisions received Oct 17, 2016; accepted for publication Oct 20, 2016; \\ available ahead of print March 23, 2017. \\ Address for reprints: Luca A. Vricella, MD, FACS, Division of Cardiac Surgery, The Johns Hopkins University \\ Hospital, 1800 Orleans St, Baltimore, MD, 21287 (E-mail: lvricella@jhmi.edu). \\ J Thorac Cardiovasc Surg 2017;154:207-9 \\ 0022-5223/\$36.00 \\ Copyright (c) 2017 by The American Association for Thoracic Surgery \\ http://dx.doi.org/10.1016/j.jtcvs.2016.10.108
}

\begin{abstract}
"If you can look into the seeds of time, and say which grain will grow and which will not, speak then to me..." -William Shakespeare
\end{abstract}

Macbeth, Act I, Scene 3, Line 58

As adult and congenital cardiac surgeons, we are often called to evaluate and treat young patients with thoracic aortic aneurysms (TAAs) and carry, together with our colleagues in cardiology, the critical burden of deciding whether an operation should be advocated or expectant management should be preferred. The decision to postpone an operation on the basis of absolute largest aortic diameter, underlying condition, and family history of aortic catastrophe should be made in adherence to established guidelines when present. Defining and following a decision-making algorithm seems relatively straightforward for the seemingly worse cases of genetic, syndromic aortopathies, such as Marfan syndrome (MFS), Loeys-Dietz syndrome, and Ehlers-Danlos syndrome, among others. ${ }^{1}$ A large population of patients still challenges us to practice evidence-based medicine, however, mainly composed of patients who do not present with a phenotype that links them directly to aortic root enlargement. In fact, patients with bicuspid aortic valve (BAV) and proximal aortic aneurysms and those with nonsyndromic TAAs (NS-TAAs) are still at high risk for aortic dissection and rupture. To add further to the difficulty in following a therapeutic algorithm, we must also include patients with repaired conotruncal anomalies (truncus arteriosus, tetralogy of Fallot, and transposition of the great arteries) and those with late neoaortic root enlargement after the Ross procedure or even the Norwood procedure.

The April 2016 issue of the Journal ${ }^{2}$ contains a summary of the guidelines for ascending aortic replacement in the in the setting of a BAV, specifically in the absence of significant stenosis or regurgitation. A joint task force of representatives of the American Heart Association and the American College of Cardiology was created to sort out the conflicting indications included in the 2010 and 2014 guidelines of the American Heart Association, the American College of Cardiology, and collaborating societies, and to assign class of

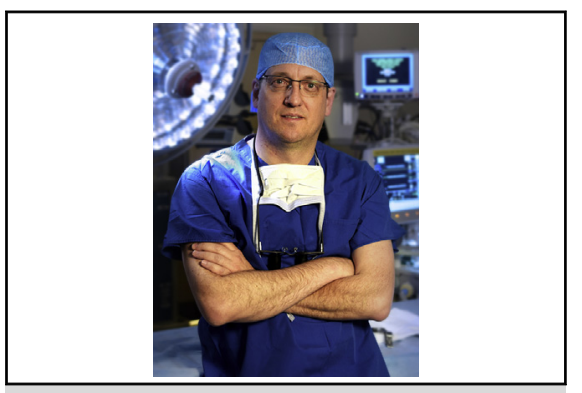

Luca A. Vricella, MD, FACS

Central Message

Guidelines for patients with nonsyndromic aortic aneurysms are not well established. Recent data suggest that we should perhaps be more aggressive in indicating prophylactic aortic aneurysm repair.

See Editorial Commentary page 210.

See Editorial page 205.

recommendation $(\mathrm{COR})$ and level of evidence ( $\mathrm{LOE})$ values to different clinical scenarios. In summary, (1) operative intervention to replace the aortic root in patients without symptoms is indicated if the aortic diameter is greater than $5.5 \mathrm{~cm}$ (COR I, strong; LOE B-NR, moderate, based on nonrandomized trials and meta-analyses). (2) Aortic replacement is indicated (COR $\mathrm{IIa}$, moderate; LOE $\mathrm{B}-\mathrm{NR}$ ) when the maximal aortic diameter is greater than $5.0 \mathrm{~cm}$ in the setting of a family history of aortic dissection or when the yearly increment in diameter exceeds $0.5 \mathrm{~cm}$. Interestingly, the 2016 guidelines' clarification also indicates that intervention in this particular circumstance is reasonable if the patient is cared for in an established aortic center. Finally, (3) replacement is also reasonable if the aorta exceeds $4.5 \mathrm{~cm}$ during concomitant aortic valve repair or replacement (COR IIa; LOE C-EO, determined by expert opinion). In light of these recommendations, one would argue that lowering the threshold for prophylactic aortic replacement to $5.0 \mathrm{~cm}$ for patients with BAV seems quite reasonable, as also reported in 2015 by the Cleveland Clinic group, who added a ratio of cross-sectional area to height greater than $10 \mathrm{~cm}^{2} / \mathrm{m}$ as another marker of increased risk of aortic catastrophe. ${ }^{3}$

More recently, a group of young patients with inherited NS-TAAs has emerged who have a paucity of somatic 
features but a clear predisposition toward root enlargement, associated with mutations of several genes associated with the transforming growth factor $\beta$ signaling pathway, including among others the myosin heavy chain 11 gene (MYH11) and the smooth muscle $\alpha$ actin gene (ACTA2). ${ }^{4}$ Whereas there are established guidelines for patients with TAAs and connective tissue disorders or BAV, the natural history of the disease in patients with NS-TAAs is largely uncharted territory. In a recent report in the Journal of the American College of Cardiology, Sherrah and colleagues ${ }^{5}$ attempted to define the risk of rupture and surgical outcomes of patients with NS-TAAs, relative to that of patients with BAV and MFS. In that report, the outcomes of 311 patients with NS-TAAs diagnosed between 1988 and 2014 were compared with those of 221 and 228 patients with MFS and BAV, respectively. Mutations in culprit gene sequences were documented in only $17 \%$ (most recent patients) of the NS-TAAs cohort, and, much as in BAV, aneurysmal dilation of the ascending aorta was more common above the aortic root. Patients were older at the time of presentation, and their aortas were larger, perhaps because of the delay in diagnosis secondary to the lack of syndromic phenotypic features. Just like patients in the MFS group, patients with NS-TAAs were more likely to have a family history of aneurysm $(62.7 \%)$ or dissection $(23.5 \%)$; furthermore, patients with NS-TAAs represented the vast majority of patients with aortic dissection $(77.1 \%)$ as well as of patient death at the time of initial presentation (73/760; 79.5\%). Stanford type B aortic dissections were also twice as frequent in patients with NS-TAAs than in patients with MFS (6.9\% vs 3.3\%). Interestingly, in a comparison of the latter 2 groups, the last known aortic diameter at the time of dissection was found to be smallest in the NS-TAA group $(47.9 \pm 12.9 \mathrm{~mm})$. In the group undergoing clinical surveillance, late mortality in the NS-TAA group was comparable to that of patients with MFS, even when patients with initial aortic dissection were excluded. The risk of late mortality in the MFS group was 4-fold that of the group with BAV, but it was only 2 times higher than that in patients with NS-TAAs. Among patients who survived an initial aortic dissection, late mortality was also highest in the NS-TAA group. Family history of aortic catastrophe plays an important role in the natural history of aneurysms in patients with NS-TAAs, and this association should prompt investigation of first-degree relatives and a push for aggressive surgical management, perhaps more similar to that currently indicated for patients with connective tissue disorders than to that currently indicated for patients with BAV.

Patients with aortic root aneurysms after repair of conotruncal anomalies are yet another emerging group of patients for whom indications for aortic root or neoaortic root replacement are poorly defined on the basis of aortic size alone. ${ }^{6}$ These patients have a combination of intrinsic, genetically determined weakness of the aortic wall ${ }^{7}$ and, in some cases, the cumulative wall stress caused by years of exposure to systemic pressure of a neoaortic root that began life as a pulmonary artery trunk. Most patients will have early root enlargement, followed by stabilization and continued growth that parallels somatic growth. But should we be intervening in a patient with repaired tetralogy of Fallot who has maximal aortic diameter of $5.2 \mathrm{~cm}$ and a BAV? Unfortunately, we have very limited data on the propensity of these patients toward an aortic catastrophe. Although reports of dissection and rupture have surfaced in the literature, the risk appears to be relatively low, in fact much lower than in patients with connective tissue disorders or with NS-TAAs. To place things in perspective, Frischhertz and coworkers ${ }^{8}$ reviewed all hospital admissions for the state of Texas between 1999 and 2012, and they found just 214 patients with congenital heart disease out of 12,016 admissions with aortic dissection and rupture $(1.8 \%)$. Among patients with congenital heart disease (excluding BAV) only 6 had conotruncal abnormalities ( $3 \%$ ), thus representing $0.05 \%$ of all cases of dissection or rupture. When this set of patients is added to the 11 patients with aortic catastrophe reported in the literature before 2015, there are 17 cases of rupture in this particular group, with the vast majority having had complications occur at very large diameters $(60-90 \mathrm{~mm})$. We should perhaps be more conservative in treating these patients, following them up longitudinally and intervening at larger diameters. We must be aware, however, that most of them will eventually come to surgical reintervention because of complications related to their aortic or neoaortic valve.

For these 3 groups of patients, it has been the preference at my institution, The Johns Hopkins University Hospital, to perform valve-sparing aortic root replacement procedures, ${ }^{9}$ assuming integrity of the aortic or neoaortic valve and the absence of obvious contraindications. The excellent intermediate-term results of these procedures are now well documented, in particular for patients with connective tissue disorders ${ }^{10}$ and even for those with BAVs. When enlargement is confined to the ascending aorta (as often seen in patients with a BAV) and the sinuses are not thinned, however, we would replace the diseased segment with perhaps a graft extension into the noncoronary sinus. As mentioned previously, patients with congenital heart disease will more frequently present with aortic or neoaortic valve regurgitation. In this scenario, we have more often leaned toward aortic valve replacement with preservation of the aortic or neoaortic root (when not in excess of $5.5 \mathrm{~cm}$ and with stable diameter and normal wall thickness); otherwise, we have more frequently opted for composite root replacement rather than valve-sparing root replacement. Reoperations on patients with congenital heart disease can be quite challenging, and the anatomy is often 
nearly prohibitive for valve reimplantation, even if the valve is relatively undiseased; a mechanical or biologic prosthesis thus might prove to be a much more durable solution for this group of patients, rather than attempting a triumph of technique over judgment.

\section{Conflict of Interest Statement}

Author has nothing to disclose with regard to commercial support.

\section{References}

1. Zanotti G, Vricella L, Cameron D. Thoracic aortic root aneurysm syndrome in children. Semin Thorac Surg Pediatr Card Surg Annu. 2008;11-21.

2. $2010 \mathrm{ACCF} / \mathrm{AHA} / \mathrm{AATS} / \mathrm{ACR} / \mathrm{ASA} / \mathrm{SCA} / \mathrm{SCAI} / \mathrm{SIR} / \mathrm{STS} / \mathrm{SVM}$ Guidelines for the Diagnosis and Management of Patients With Thoracic Aortic Disease Representative Members, Hiratzka LF, Creager MA, Isselbacher EM, Svensson LG, 2014 AHA/ACC Guideline for the Management of Patients With Valvular Heart Disease Representative Members, Nishimura RA, Bonow RO, Guyton RA, Sundt TM III. Surgery for aortic dilatation in patients with bicuspid aortic valves: a statement of clarification from the American College of Cardiology/ American Heart Association Task Force on Clinical Practice Guidelines. J Thorac Cardiovasc Surg. 2016;151:959-66.
3. Wojnarski CM, Svensson LG, Roselli EE, Idrees JJ, Lowry AM, Ehrlinger J, et al. Aortic dissection in patients with bicuspid aortic valve-associated aneurysms. Ann Thorac Surg. 2015;100:1666-73; discussion 1673-4.

4. Saratzis A, Brown MJ. The genetic basis for aortic aneurysmal disease. Heart. 2014; 100:916-22.

5. Sherrah AG, Andvik S, van der Linde D, Davies L, Bannon PG, Padang R, et al Nonsyndromic thoracic aortic aneurysm and dissection: outcomes with Marfan syndrome versus bicuspid aortic valve aneurysm. J Am Coll Cardiol. 2016;67:618-26.

6. Stulak J, Dearani J, Burkhart H, Sundt T, Connolly H, Schaff H. Does the dilated ascending aorta in an adult with congenital heart disease require intervention? J Thorac Cardiovasc Surg. 2010;140(6 Suppl):S52-7; discussion S86-91.

7. Chowdhury U, Mishra A, Ray R, Kalaivani M, Reddy S, Venugopal P. Histopathologic changes in ascending aorta and risk factors related to histopathologic conditions and aortic dilatation in patients with tetralogy of Fallot. J Thorac Cardiovasc Surg. 2008;135:69-77. 77.e1-11.

8. Frischhertz B, Shamszad P, Pedroza C, Milewicz D, Morris S. Thoracic aortic dissection and rupture in conotruncal cardiac defects: a population-based study. Int J Cardiol. 2015;184:521-7.

9. Cameron DE, Vricella LA. Valve-sparing aortic root replacement in Marfan syndrome. Semin Thorac Cardiovasc Surg Pediatr Card Surg Annu. 2005; $103-11$.

10. Price J, Magruder JT, Young A, Grimm JC, Patel ND, Alejo D, et al. Long-term outcomes of aortic root operations for Marfan syndrome: a comparison of Bental versus aortic valve-sparing procedures. J Thorac Cardiovasc Surg. 2016;151: 330-6. 